\title{
Critical mechanisms for the formation of extreme arctic sea-ice extent in the summers of 2007 and 1996
}

\author{
Xiquan Dong $\cdot$ Behnjamin J. Zib $\cdot$ Baike Xi $\cdot$ \\ Ryan Stanfield $\cdot$ Yi Deng $\cdot$ Xiangdong Zhang $\cdot$ \\ Bing Lin · Charles N. Long
}

Received: 19 February 2013/Accepted: 14 August 2013/Published online: 29 August 2013

(c) The Author(s) 2013. This article is published with open access at Springerlink.com

\begin{abstract}
Along with significant changes in the Arctic climate system, the largest year-to-year variation in sea-ice extent (SIE) has occurred in the Laptev, East Siberian, and Chukchi seas (defined here as the area of focus, AOF), among which the two highly contrasting extreme events were observed in the summers of 2007 and 1996 during the period 1979-2012. Although most efforts have been devoted to understanding the 2007 low, a contrasting high September SIE in 1996 might share some related but opposing forcing mechanisms. In this study, we investigate the mechanisms for the formation of these two extremes and quantitatively estimate the cloud-radiation-water vapor feedback to the sea-ice-concentration (SIC) variation utilizing satellite-observed sea-ice products and the NASA
\end{abstract}

X. Dong

GCESS, Beijing Normal University, Beijing, China

X. Dong $(\bowtie) \cdot$ B. J. Zib · B. Xi · R. Stanfield

The Department of Atmospheric Sciences, University of North Dakota, 4149 University Ave. Stop 9006, Grand Forks,

ND 58202-9006, USA

e-mail: dong@aero.und.edu

Y. Deng

School of Earth and Atmospheric Sciences, Georgia Institute of Technology, Atlanta, GA, USA

X. Zhang

Department of Atmospheric Sciences, International Arctic Research Center, University of Alaska Fairbank, Fairbank, AK, USA

B. Lin

NASA Langley Research Center, Hampton, VA, USA

C. N. Long

DOE Pacific Northwest National Laboratory,

Richland, WA, USA
MERRA reanalysis. The low SIE in 2007 was associated with a persistent anticyclone over the Beaufort Sea coupled with low pressure over Eurasia, which induced anomalous southerly winds. Ample warm and moist air from the North Pacific was transported to the AOF and resulted in positive anomalies of cloud fraction (CF), precipitable water vapor (PWV), surface LWnet (down-up), total surface energy and temperature. In contrast, the high SIE event in 1996 was associated with a persistent low pressure over the central Arctic coupled with high pressure along the Eastern Arctic coasts, which generated anomalous northerly winds and resulted in negative anomalies of above mentioned atmospheric parameters. In addition to their immediate impacts on sea ice reduction, CF, PWV and radiation can interplay to lead to a positive feedback loop among them, which plays a critical role in reinforcing sea ice to a great low value in 2007. During the summer of 2007, the minimum SIC is $31 \%$ below the climatic mean, while the maximum $\mathrm{CF}$, LWnet and PWV can be up to $15 \%, 20 \mathrm{Wm}^{-2}$, and $4 \mathrm{~kg} \mathrm{~m}^{-3}$ above. The high anti-correlations $(-0.79,-0.61$, -0.61 ) between the SIC and CF, PWV, and LWnet indicate that $\mathrm{CF}, \mathrm{PWV}$ and $\mathrm{LW}$ radiation are indeed having significant impacts on the SIC variation. A new record low occurred in the summer of 2012 was mainly triggered by a super storm over the central Arctic Ocean in early August that caused substantial mechanical ice deformation on top of the long-term thinning of an Arctic ice pack that had become more dominated by seasonal ice.

Keywords Trigger and cause of Arctic sea ice retreat - Cloud-radiation-water vapor feedback to the sea-ice-concentration variation - Extreme Arctic seaice extent formation mechanisms - Triggered by atmospheric forcings - Enhanced clouds-radiationPWV feedback 


\section{Introduction}

The global mean surface temperature has increased $0.6-0.7{ }^{\circ} \mathrm{C}$ since the mid-1960s (Kennedy et al. 2007), and during the same period the temperature over the Arctic region (north of $60^{\circ}$ ) has risen by $1.9-2.0^{\circ} \mathrm{C}$, even more during the winter and spring months (RichterMenge et al. 2008; Graversen et al. 2008). A warming Arctic is undergoing significant environmental change, mostly evidenced by the reduction of Arctic sea-ice extent (SIE) during summer. Sea-ice plays a major role in the Arctic climate system by regulating the amount of insolation received at the surface (Porter et al. 2010 and 2011) and the salinity of sea surface water, which is one of the keys for thermohaline circulations (Levermann et al. 2007). Changes in location and extent of sea-ice lead to perturbations of surface albedo and ocean-atmosphere interactions that in turn impact the climate system (Deser et al. 2000; Donohoe and Battisti 2011). Several factors are believed to have significant impacts on the Arctic seaice variation. For example, dynamic export and long-term thinning of sea ice may result in amplified responses, such as the 2007 low and 2012 record low SIEs (Lindsay et al. 2009; Drobot et al. 2008; Giles et al. 2008; Zhang et al. 2008a; Maslanik et al. 2007a, b; Kwok 2008; NSIDC). North Pacific and North Atlantic warm water intrusions (e.g., Shimada et al. 2006; Zhang et al. 2008b; Polyakov et al. 2010) and atmospheric forcings are also believed to play an important role on the Arctic sea-ice variation. The atmospheric forcing parameters include large-scale atmospheric circulation patterns (Zhang et al. 2008b; Ogi et al. 2008; Deser et al. 2000; Overland and Wang 2010), atmospheric transport of heat and moisture (Zhang et al. 2008b; Graversen et al. 2008, 2011), wind stress (Ogi et al. 2008; Haas and Eicken 2001), and surface radiative and turbulent fluxes (Francis and Hunter 2006; Graversen et al. 2011; Porter et al. 2010, 2011). The relative importance of each parameter and the underlying causes of Arctic sea-ice variation has, however, not been well evaluated, in particular for the two opposing extreme events in 2007 and 1996.

For the past 30 years, passive microwave sensors have monitored sea-ice and provided an important tool for investigating its seasonal and inter-annual variability over the Arctic. While the annual mean SIE has decreased more than one million square kilometers in the last three decades, the decrease in September SIE is roughly twice the magnitude of the annual change for the period 1979-2012. The summer of 2007 caught much attention of the Arctic and global research community (e.g., Kay et al. 2008; Kay and Gettleman 2009; Comiso et al. 2008; Schweiger et al. 2008a; Zhang et al. 2008a, b; Graversen et al. 2011; Cuzzone and Vavrus 2011) as September SIE plummeted to a minimum of 4.3 million $\mathrm{km}^{2}$, or nearly $31 \%$ below the 1979-2012 average.

A number of studies have investigated the 2007 low and concluded that it was caused by an unusually persistent weather pattern on top of decades of sea ice thinning (e.g., Maslanik et al. 2007a; Zhang et al. 2008a, b; Graversen et al. 2011, Overland and Wang 2010). For example, Kay et al. (2008) showed that an anomalous high pressure over the Beaufort Sea resulted in relatively clear skies and more downwelling shortwave (SW) flux reaching the surface and suggested that reduced cloud fraction (CF) and enhanced downwelling SW flux had contributed significantly to the 2007 low. However, Schweiger et al. (2008) demonstrated with an ice-ocean model that reduced $\mathrm{CF}$ and enhanced downwelling SW flux had contributed little to the 2007 low. More specifically, they argued that the impact of enhanced downwelling SW flux was small and largely confined to areas north of the ice edge, where surface albedo remained high and additional absorption of solar radiation by the surface was thus minimal. On the other hand, it was first documented by Amback (1974) and later on confirmed by Francis et al. (2005) and Graversen et al. (2011) that downwelling LW flux contributed more to the reduction of SIE than downwelling SW flux.

Although most efforts have been devoted to understanding the 2007 low, a contrasting high September SIE in the observational record might share some related but opposing forcing mechanisms. Based on the 34-year trend (1979-2012) of September SIE and the de-trended sea-ice extent (not shown) record, 2007 and 1996 are selected respectively as the low and high September SIE years for analysis in this study. Notice that we aim to identify the causes, mechanisms and feedback processes responsible for these two opposite extreme years, not sea ice anomalies in general in this study. As demonstrated in Fig. 1, the seaice concentrations (SIC) in these two selected years exhibited the largest contrast over the Laptev, East Siberian, and Chukchi seas. We therefore focus on this region $\left(70-90^{\circ} \mathrm{N}, 90-210^{\circ} \mathrm{E}\right)$ and define it as the area of focus (AOF). The SICs in these two selected years, as well as other extreme years, have experienced the largest fluctuations ( -50 to $50 \%$ ) over the AOF, which could be attributable to thin sea ice and dominated seasonal ice in this region. Thin and seasonal ice is vulnerable to external forcings from either atmosphere or ocean. For example, the 2007 low was strongly contributed by anomalous southerly winds, while the 1996 high was associated with anomalous northerly winds across the AOF (shown and discussed in Fig. 3). Note that previous studies (e.g., Kay et al. 2008; Kay and Gettleman 2009) of the 2007 low tend to focus more on the Western Arctic region. Sea-ice in the AOF is generally transported to join the Transpolar Drift and exported out of the Arctic Ocean through the Fram Strait 
between Greenland and Svalbard during low sea-ice years (Harder et al. 1998; Peixoto and Oort 1992). The extent and variability of sea-ice in these seas strongly influence the basin-scale summer minima and are important for oceanice-atmosphere processes (Haas and Eicken 2001).

In this study we explore in detail the underlying processes driving the 2007 and 1996 extreme events, and identify similarities and differences between these 2 years with respect to the major factors and atmospheric conditions contributing to the formation of the SIE extremes. We will also briefly discuss the 2012 record low and compare the atmospheric conditions and parameters in 2012 with those in 2007. We further investigate the mechanisms for triggering and causing the 2007 low, such as the onset was triggered by a persistent large-scale atmospheric circulation anomaly during spring, and later on the sea ice melting was accelerated by a positive cloud-radiation-PWV (precipitable water vapor) feedback over the AOF during summer and early autumn.

\section{Data sets}

\subsection{Sea-ice}

The monthly mean sea ice extent (SIE) and concentration (SIC) were provided by the National Snow and Ice Data Center (NSIDC) using Nimbus-7 SSMR and DMSP SSM/I Passive Microwave Data (SSMR available since October
1978) and Near-Real-Time Special Sensor Microwave/ Imager (SSM/I) Polar Gridded SIC dataset (Cavalieri et al. 2004). The SIC is defined as the percentage of ice cover over a grid box of $25 \times 25 \mathrm{~km}^{2}$, which provides more details into the daily variability of the sea-ice over a specific grid box compared to SIE. SIE is an area integral of a grid box with SIC greater than $15 \%$, which can provide information about the sea-ice coverage over the entire Arctic Ocean.

\subsection{MERRA reanalysis}

NASA has recently released MERRA Modern-Era Retrospective Analysis for Research and Applications (MERRA) reanalysis dataset based on the Goddard Earth Observing System data Analysis System Version 5 (GEOS-5 DAS, Bosilovich et al. 2008). Rienecker et al. (2008, 2011) thoroughly described the MERRA project, as well as the MERRA/GEOS-5 numerical model and data assimilation system, including the GEOS-5 atmospheric general circulation model and the Gridpoint Statistical Interpolation (GSI) atmospheric analysis developed jointly with NOAA/ NCEP/EMC. Also incorporated into GEOS-5 is Incremental Analysis Updates (IAU) (Bloom et al. 1996) to slowly adjust the model states toward the observed state. In addition to the conventional observations (radiosonde, station, aircraft, ship), the MERRA reanalysis takes advantage of a variety of recent satellite observations since 1979, such as NASA's Earth Observing System, SSM/I

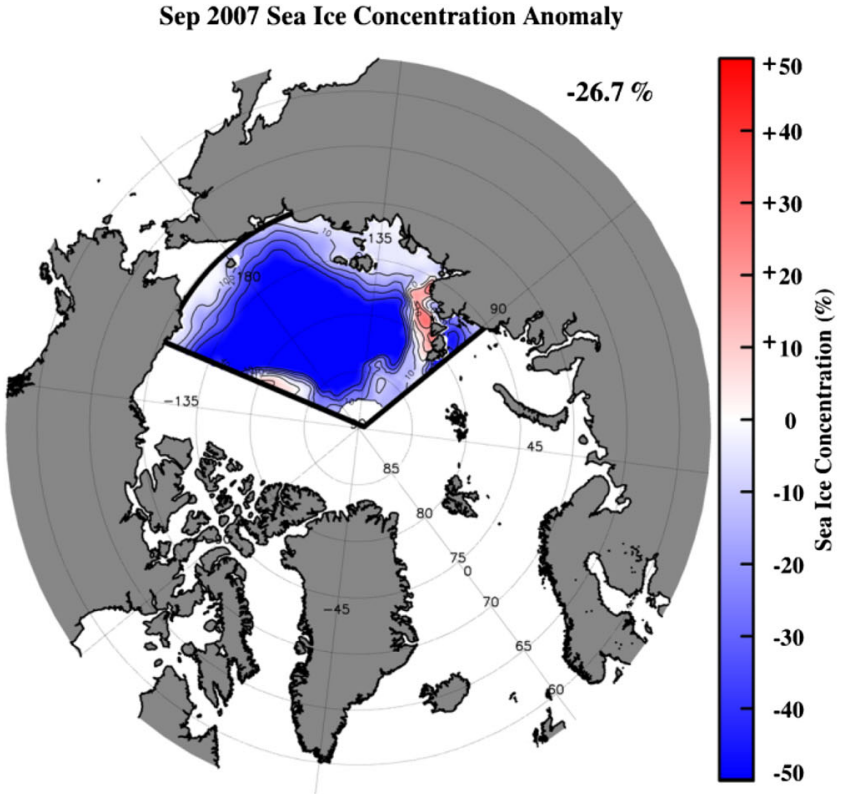

Fig. 1 September SIC anomalies over the AOF for 2007 (left) and 1996 (right) against the climatic mean of 1979-2012. The AOF includes the Laptev, East Siberian, and Chukchi seas $\left(70-90^{\circ} \mathrm{N}\right.$, $\left.90-210^{\circ} \mathrm{E}\right)$ those were experienced the largest variation in SIC from

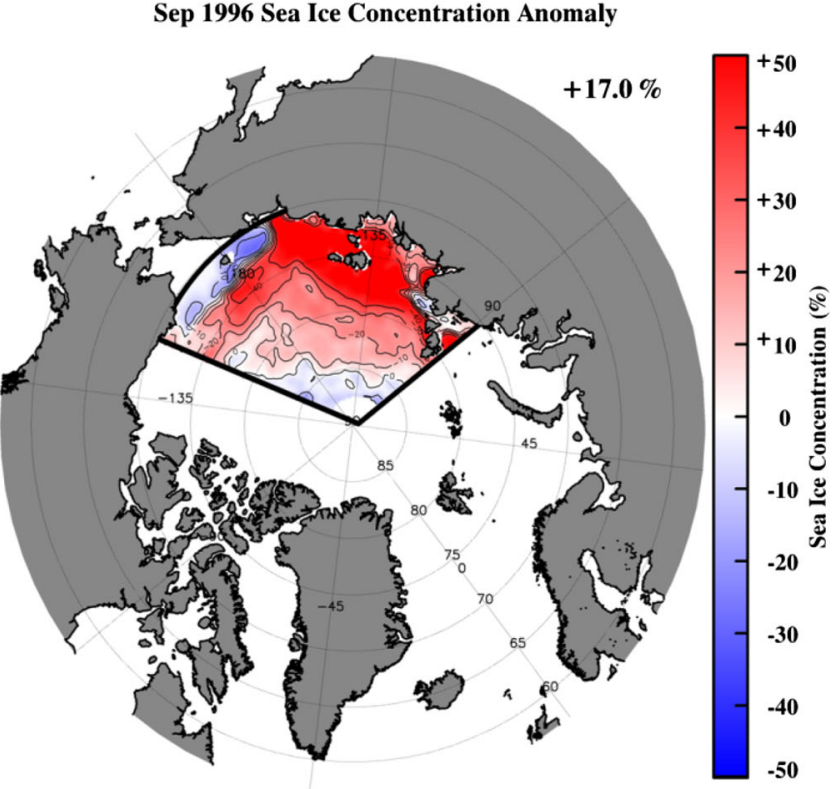

year-to-year. The SIC data used in this study were obtained from the National Snow and Ice Data Center (NSIDC, nsidc.org) in Boulder, $\mathrm{CO}$ 
radiances, TIROS Operational Vertical Sounder (TOVS) radiances, Atmospheric Infrared Sounder (AIRS) radiances, and scatterometer wind retrievals (for more information, see Figs. 3 and 4 of Rienecker et al. 2011) with a focus on improving estimates of the global energy and water budgets. In this study, hourly 2-dimensional diagnostics from MERRA at $2 / 3^{\circ} \times 1 / 2^{\circ}$ horizontal resolution is used. The SW and LW radiation parameterizations used in MERRA are documented in Chou and Suarez (1999) and Chou et al. (2001), respectively.

\subsection{Assessment of MERRA reanalysis}

The accuracy of the re-analysis product is critical for diagnosing past weather and climate events, especially extremes that occur over remote regions. To have a reliable application of MERRA cloud and radiation fluxes in the study of the Arctic sea-ice state, it is important to have a reasonable estimate of the errors and accuracies of the reanalyzed cloud and radiative properties. There are a number of such evaluation studies in the recent MERRA special issue (Bosilovich et al. 2011; Rienecker et al. 2011; Robertson et al. 2011), some focused on the Arctic regions (Cullather and Bosilovich 2011 and 2012; Vavrus et al. 2012). As Rienecker et al. (2011) pointed out, one of the strengths of the most recent reanalyses is overall better representations of the inter-annual variability in the atmospheric state on monthly to seasonal time scales, such as 500-hPa height, vertical velocity and large-scale atmospheric transports. However, the accuracy of the representation strongly depends on both the specific variables and regions under consideration. Robertson et al. (2011) analyzed the effects of the changing observing system on MERRA's energy and water fluxes where the re-analyzed results are still quite sensitive to observing system changes. For example, the MERRA re-analyzed precipitation has a series of jumps and different trends that are mainly associated with the SSM/I and AMSU-A changes (see table 1 of Rienecker et al. 2011). Applying principal component regression to the data largely reduces the jumps and different trends in MERRA precipitation and radiative fluxes, making the adjusted MERRA precipitation compare more favorably with the Global Precipitation Climatology Project (Robertson et al. 2011).

To quantify the errors and uncertainties in the MERRA re-analyzed clouds and radiation budget over the Arctic regions, Zib et al. (2012) evaluated the MERRA results over two surface sites using more than a decade of groundbased observations. They compared the MERRA re-analyzed $\mathrm{CF}$, surface radiative fluxes, and surface air temperature (SAT) with high-quality Baseline Surface Radiation Network (BSRN, Ohmura et al. 1998) data from Barrow, AK (BAR, $\left.71.32^{\circ} \mathrm{N}, 156.6^{\circ} \mathrm{W}\right)$ for the period
1994-2008. The re-analyzed CFs are $2.7 \%$ higher than those observed by ceilometer at BAR $(74.6 \%)$ with large positive biases during winter months and negative biases during summer months. Compared to the observed annual averages of downwelling SW flux $\left(97.1 \mathrm{Wm}^{-2}\right)$ and LW flux $\left(240.2 \mathrm{Wm}^{-2}\right)$, the re-analyzed downwelling SW and $\mathrm{LW}$ fluxes have negative biases of -9.7 and $-2.2 \mathrm{Wm}^{-2}$, respectively. Notice that downward fluxes are positive and upward are negative in this study. The SATs between observations and reanalysis agree to $0.3{ }^{\circ} \mathrm{C}$. It is expected that the systematic biases and parameterization errors of MERRA can be partially removed when the net fluxes (down-up) and anomalies (differences from overall mean) are used as in this study.

However, there is one artifact in MERRA reanalysis that cannot be removed from the anomalies. As pointed out by Cullather and Bosilovich (2012), the MERRA analysis has a very simplistic sea-ice albedo parameterization (fixed at 0.6 for all ice). This simple parameterization may generate considerable biases in upwelling and downwelling SW fluxes, which lead to problems in the evaluation of the icealbedo feedback process. The observed snow/ice albedos at the BSRN Barrow site (Zib et al. 2012, Dong et al. 2010) and during the Surface Heat Budget of the Arctic Ocean (SHEBA) experiment (Intrieri et al. 2002) are around $0.80-0.90$. The downwelling SW flux is primarily determined by the following three parameters: cloud fraction and optical depth, and surface albedo. When the surface is covered by snow/ice and CF is high, the downwelling SW flux at the surface includes a significant contribution from the surface reflected SW flux due to multiple reflections between cloud base and highly reflective surface. Therefore, the prescribed surface albedo (0.6) in MERRA leads to less upwelling SW flux over the snow and ice covered portions of the Arctic, particularly during the spring and early summer months, and results in less downwelling SW flux too.

To quantitatively estimate the errors in the MERRA reanalyzed downwelling and upwelling SW and LW fluxes over the entire Arctic region $\left(70-90^{\circ} \mathrm{N}\right)$, we compare the MERRA reanalyzed radiative fluxes with NASA Clouds and Earth's Radiation Energy System (CERES) generated Energy Balanced and Filled (EBAF) monthly mean surface fluxes for the period 2000-2010. The CERES EBAF monthly mean surface fluxes are calculated by the modified Fu-Liou code with the inputs of the CERES retrieved cloud properties and daily surface albedo. The CERES derived TOA fluxes are used as constraints during the calculation. The surface EBAF fluxes have been compared with surface observations (For more details, visit NASA CERES Science Team meetings at http://ceres.larc.nasa.gov/scienceteam-meetings2.php?date=2013-05). Although the CERES surface EBAF fluxes are not perfect, they compare well 
with surface observations, and can be used to evaluate the MERRA reanalyzed fluxes over the Arctic.

As shown in Fig. 2, the seasonal variations of MERRA reanalyzed downwelling and upwelling LW fluxes follow the EBAF results with an annual mean difference of $\sim 5$ $\mathrm{Wm}^{-2}$. Relative larger differences $\left(\sim 10 \mathrm{Wm}^{-2}\right)$ exist in downwelling LW flux during summer months and in upwelling LW flux during winter months. For SW fluxes, MERRA results basically follow the EBAF seasonal variations and their annual mean difference is $\sim 12 \mathrm{Wm}^{-2}$. However, large negative biases $\left(\sim-30 \mathrm{Wm}^{-2}\right.$ for downwelling SW and $\sim-50 \mathrm{Wm}^{-2}$ for upwelling SW) are found during the period April-June due to the fixed ice albedo in MERRA parameterization. Therefore the MERRA SW fluxes should be treated with some degree of caution during the period April-June. The MERRA systematic biases could be removed, at least partially, when the net fluxes (down-up) and anomalies (monthly meanclimatic mean) are used in this study. For example, the annual difference in net SW flux between the EBAF $\left(42.1 \mathrm{Wm}^{-2}\right)$ and MERRA $\left(45.8 \mathrm{Wm}^{-2}\right)$ is only $3.7 \mathrm{Wm}^{-2}$. The net $\mathrm{SW}$ flux difference is also small during the period June 15-September 15, which we will focus on in this study.

The above analyses provide information about the differences between the MERRA results and EBAF datasets or the systematic biases in MERRA reanalysis, which would help us to better understand the uncertainties and robustness of research findings in this study. Meanwhile, according to its nature, the MERRA results theoretically provide physically consistent estimate of atmospheric state globally under observational constraint. It therefore helps fill out observational gaps in the observational sparse regions, such as the Arctic Ocean. In particular, there are no direct measurements of some variables like sensible and latent heat fluxes. So, we elect to mainly use the MERRA results in the following analysis.

\section{Results and discussions: inter-annual and seasonal variations}

Various atmospheric forcing parameters relevant to the Arctic sea-ice variation are examined for the two extreme events in 2007 and 1996, including large-scale atmospheric circulation pattern, thermodynamic variables, and atmospheric physical parameters. In particular, surface pressure, winds, and air temperature (SAT) are used in this study. Atmospheric precipitable water vapor (PWV), cloud fraction (CF), surface longwave net (down-up) (LWnet), shortwave net (SWnet) fluxes, and total surface energy budget (radiative + non-radiative) are also used to study the feedback mechanisms. The summer means of these parameters during 2007 and 1996 are calculated from the daily averages over the AOF from June 15 to September 15 (JJAS) and anomalies are the differences of the summer means from the corresponding summer averages during the period 1979-2012.

Figure 3 shows the MERRA re-analyzed summer (6/159/15, JJAS) anomalies of mean sea level pressure (MSLP), 10-m meridional wind speed (V), SAT, PWV, CF, surface LWnet, SWnet, and total surface energy [(LWnet + SWnet)-(SH + LH)] fluxes over the AOF in 2007 (left column) and 1996 (right column). In this study, the positive net radiative fluxes (LWnet + SWnet) represent greater downwelling flux than upwelling flux, while the upward non-radiative fluxes (sensible and latent heat fluxes, $\mathrm{SH}$ and $\mathrm{LH}$ ) are positive. Thus the positive total surface energy budget represents more energy into the earth surface. As illustrated in Fig. 3a, during the summer of 2007 a persistent anticyclone was positioned over the Beaufort Sea, coupled with an area of low pressure over the Eurasia region. Under this synoptic pattern, strong positive anomalies in meridional winds (anomalous southerly) are evident over the Chukchi and East Siberian Seas (Fig. 3b). The southerly winds across the Chukchi and East Siberian Seas transport warm (positive anomaly of SAT, Fig. 3c) and moist air (positive anomaly of PWV, Fig. 3d) from the North Pacific. The warm, moist air transported from the North Pacific and open seas has resulted in a positive anomaly of CF over the AOF (Fig. 3e), which has a significant impact on surface radiation budget. These results are consistent to the previous studies (e.g., Graversen et al. 2011; Overland et al. 2008).

During the summer of 2007, the averaged CF over the AOF was $7.1 \%$ higher than the 34-year average. The surface LWnet and SWnet fluxes were respectively 9.8 and $4.2 \mathrm{Wm}^{-2}$ higher and lower than their corresponding climatic means, resulting in a $5.6 \mathrm{Wm}^{-2}$ positive anomaly of net radiative flux (more downward). This result is consistent with previous findings (Francis et al. 2005; Dong et al. 2010) where both studies provide strong support for the finding in this study, i.e., LW effect overwhelmed SW effect over the AOF. For example, Francis et al. (2005) studied the ice edges of all six peripheral seas over Arctic and found that the LW anomalies contributed about $40 \%$ to the total variability, but the SW anomalies were overwhelmed by the LW impact when CF was high.

The positive SAT anomalies over the AOF (Fig. 3c) provide additional information reflecting increased surface total energy budget in conjunction with the drastic sea-ice retreat during the summer of 2007. In addition to advection, SAT is determined by the sum of the net radiative (SWnet and LWnet) and non-radiative fluxes [SH, LH, seaice melt and ocean heat]. Although it is difficult to directly calculate the amount of energy being used to melt sea ice 

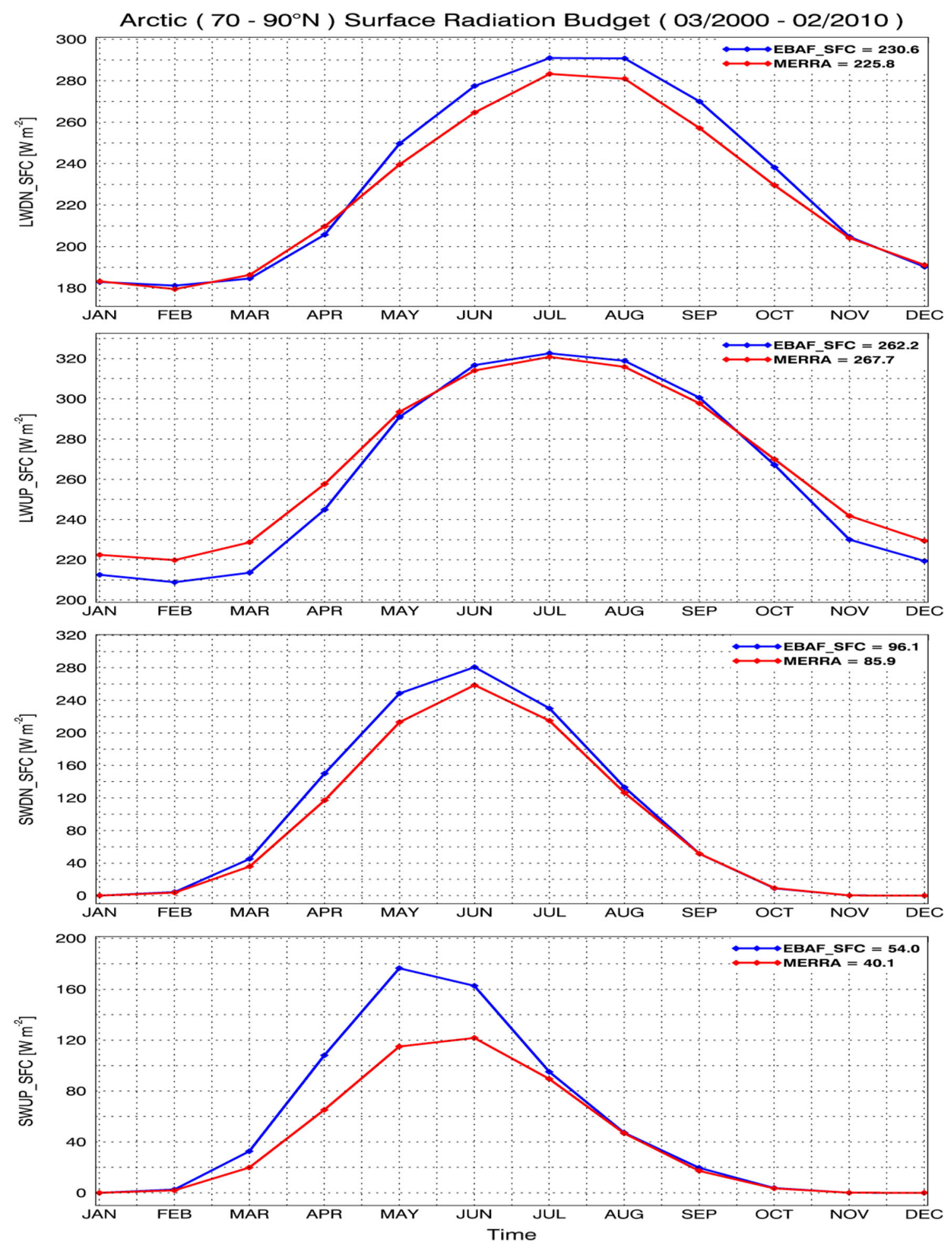

Fig. 2 Monthly means of downwelling and upwelling LW and SW fluxes over the Arctic region $\left(70-90^{\circ} \mathrm{N}\right)$ during the period 03/2000-02/2010 from the NASA CERES surface EBAF fluxes

and heat the ocean, this quantity can be derived indirectly from the net radiative, $\mathrm{SH}$, and $\mathrm{LH}$ fluxes. The total surface energy budget $[(\mathrm{LWnet}+\mathrm{SWnet})-(\mathrm{SH}+\mathrm{LH})]$ anomaly is (http://ceres.larc.nasa.gov/order_data.php) and MERRA reanalyzed results (http://gmao.gsfc.nasa.gov/products/)

7.0 $\mathrm{Wm}^{-2}$ (Fig. 3h) over the AOF during the period June 15 -September 15 , indicating that $7.0 \mathrm{Wm}^{-2}$ more energy than its climatological value was absorbed by sea ice and 
Fig. 3 a Left column a-d 2007 MERRA reanalyzed summer (6/15-9/15, JJAS) anomalies of mean sea level pressure

(MSLP), 10-m meridional wind speed (V), 2-m air temperature (SAT), and precipitable water vapor (PWV) over the Arctic ocean $\left(70-90^{\circ} \mathrm{N}\right)$, while the solid black lines cover the AOF. Right column is the same as left column except for 1996. The mean values represent the averaged anomalies over the AOF during the period June 15-September 15. b Left column e-h 2007 MERRA reanalyzed summer (6/15-9/15, JJAS) anomalies of total cloud fraction (CF), surface longwave net (down-up) flux (LWnet), surface shortwave net flux (SWnet), and total surface energy budget

([LWnet + SWnet $]-$

$[\mathrm{LH}+\mathrm{SH}]$ ) over the $\mathrm{AOF}$, where $\mathrm{LH}$ and $\mathrm{SH}$ are latent and sensible heat fluxes. Right column is the same as left column except for 1996. The positive anomalies of surface LWnet and total energy represent that the $\mathrm{AOF}$ received more LW flux and total energy in 2007 compared to their summer averages during the period 1979-2012
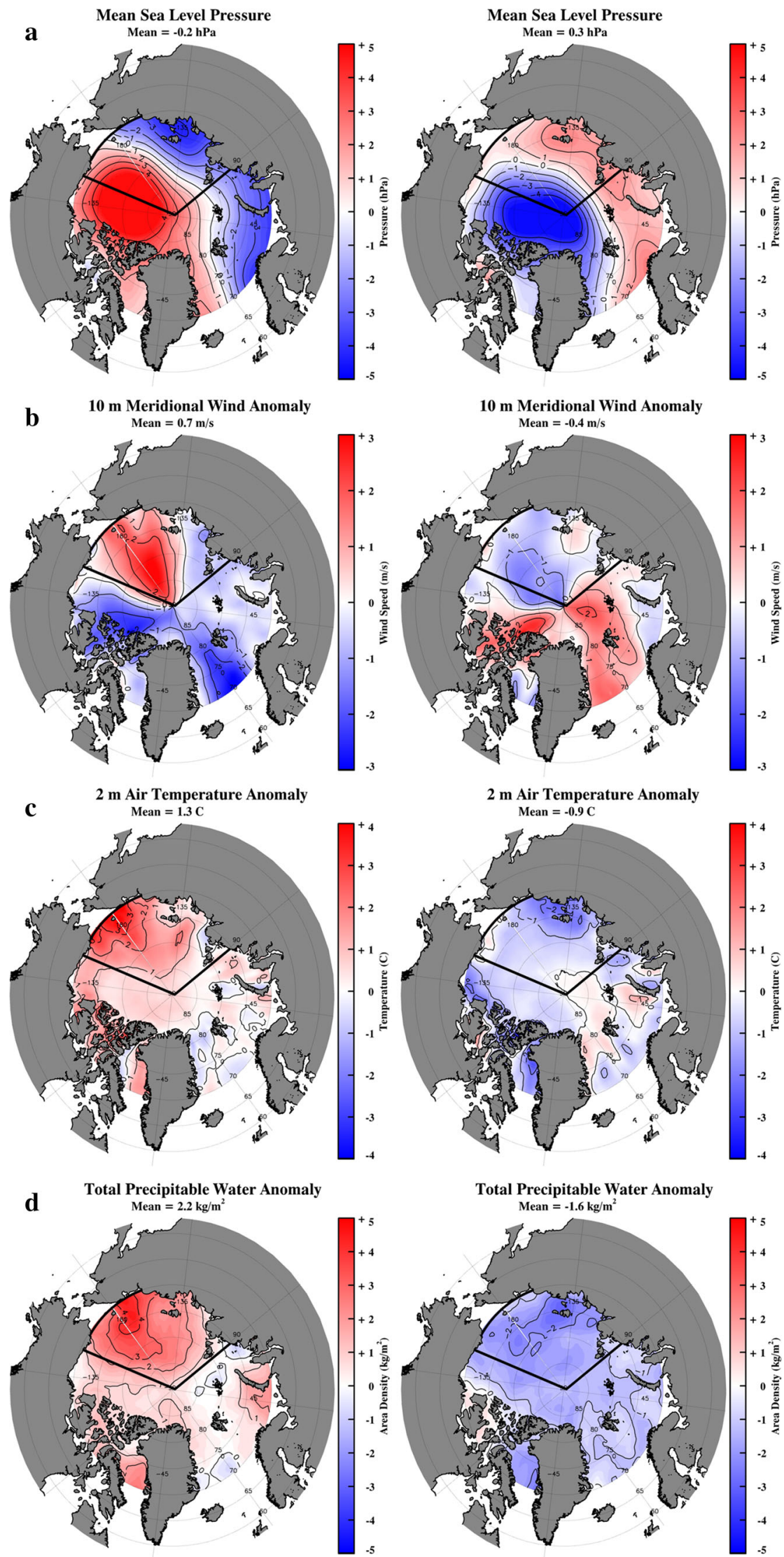
Fig. 3 continued
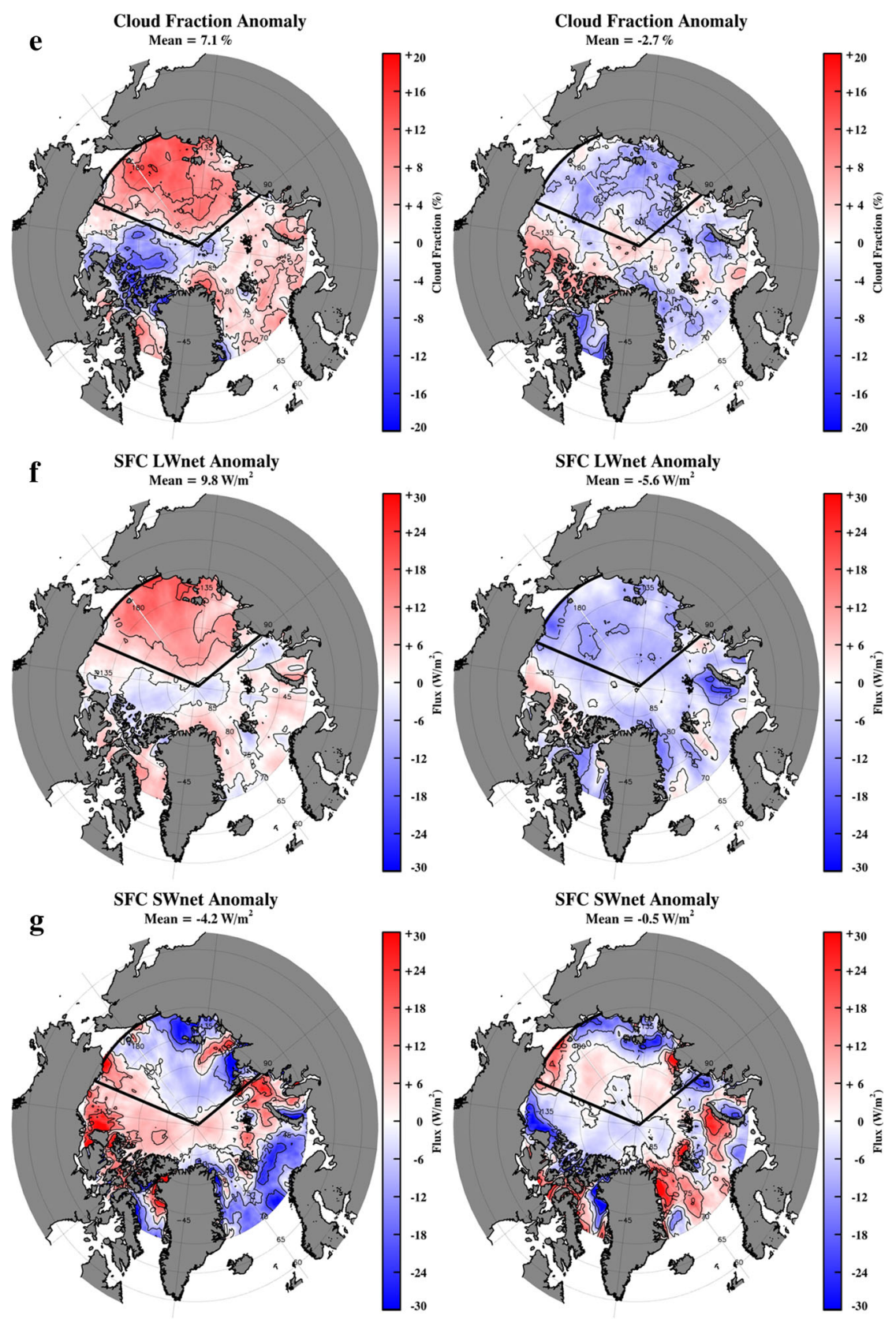

SFC SWnet Anomaly
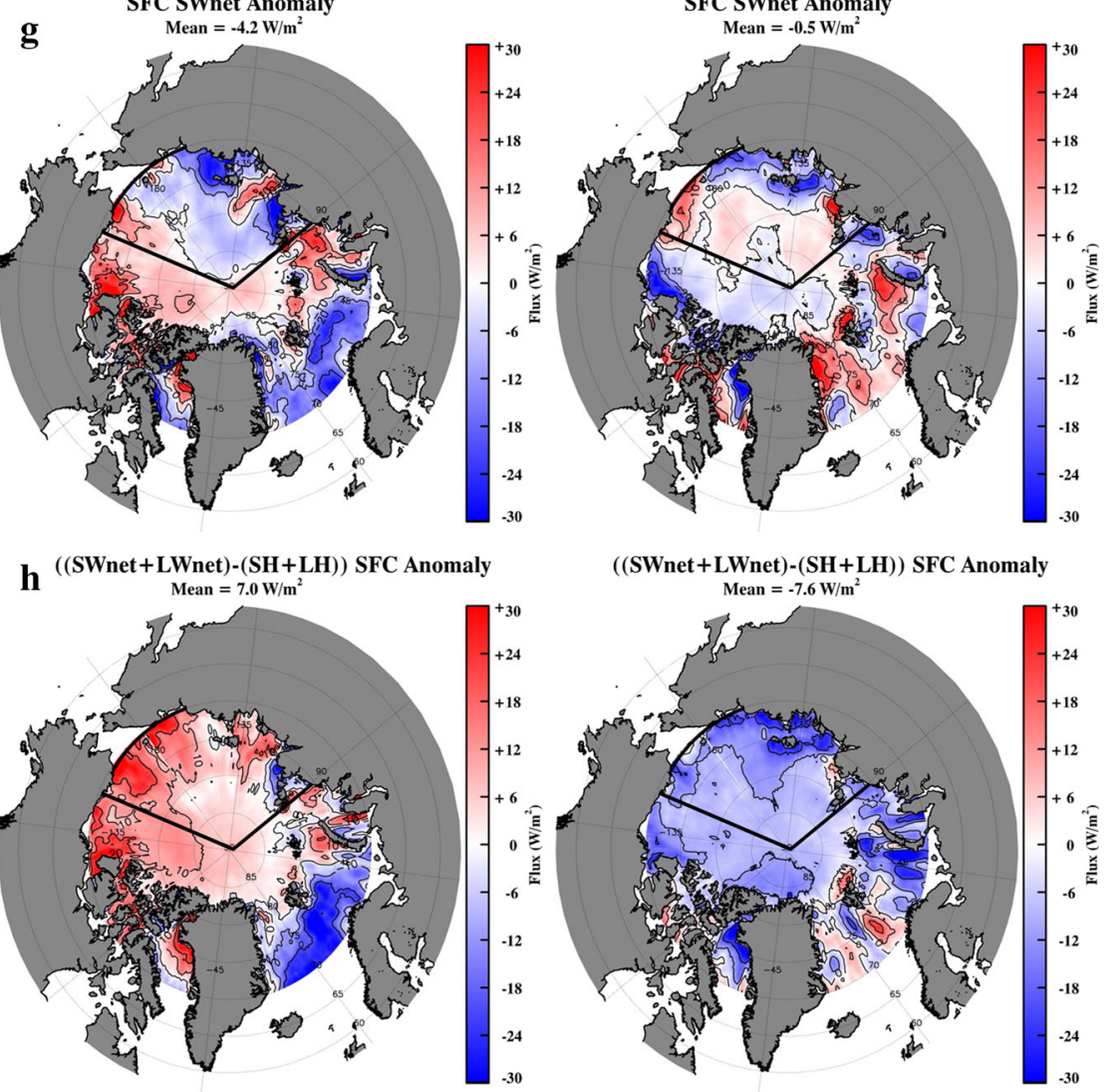
ocean. This extra $7.0 \mathrm{Wm}^{-2}$ has partially contributed to the $1.3{ }^{\circ} \mathrm{C}$ increase in SAT and the 2007 low.

Along with enhanced ocean and atmosphere heat transport from the North Pacific side, the increased surface southerly winds over the AOF (northerly winds through the Fram Strait) may also cause an increase in the Transpolar Drift favoring the export of sea-ice out of the Arctic Ocean through the Fram Strait during the summer of 2007 as demonstrated in Fig. $3 \mathrm{~b}$ and discussed in the studies of (Zhang et al. 2008a, b). When looking back to earlier years, Zhang et al. (2008b) detected a radical spatial pattern shift of the leading atmospheric circulation pattern and also found an increase in the North Atlantic warm air and water intrusion into the Arctic Ocean through the Fram Strait and the Barents Sea during 2001-2006. This abnormal dynamic process enhances Arctic Ocean and atmosphere warming and suppresses winter sea-ice production, which could be a preconditioning for the 2007 low under unusually increased surface energy budgets (more downward).

The same variables for the high September SIE in 1996 are also shown in Fig. 3 (right column). As demonstrated in Fig. 3, the anomalies of these variables in 1996 almost oppositely mirror those in 2007 , but have smaller magnitudes. Low pressure persisted over the central Arctic along with high pressure across the Eastern Arctic coastlines allowing for anomalous northerly winds across the AOF during the summer of 1996. These winds provide additional support for transporting sea-ice towards the Siberian coastline thereby weakening the transpolar drift and export from the Arctic basin through the Fram Strait (southerly winds over the Fram Strait). The total loss of $-7.6 \mathrm{Wm}^{-2}$ heat (Fig. 3h) has contributed significantly to the $0.9{ }^{\circ} \mathrm{C}$ decrease in SAT and high SIE in 1996. Note that there is a nonlinear relation between net heating and surface warming comparing $2007\left(7.0 \mathrm{Wm}^{-2}\right.$ vs. $\left.1.3^{\circ} \mathrm{C}\right)$ with 1996 $\left(-7.6 \mathrm{Wm}^{-2}\right.$ vs. $\left.-0.9^{\circ} \mathrm{C}\right)$. During the summer of 1996 Arctic surfaces were mostly covered by ice or snow, thus there were minimal interactions between ocean and the atmosphere of some heating sources, such as oceanic heat advection and deep ocean heat mixing. During the summer of 2007, the cloud-radiation-PWV feedback played an important role to increase surface temperature with more open seas. Studies (e.g, Lin et al. 2010a, b) over different climate conditions have shown that there are non-linear effects of cloud-radiation-PWV feedbacks on the climate system, especially over the Arctic regions with snow/ice covered surfaces (e.g., Curry et al. 1996).

During the review of this paper, Arctic SIE plummeted to a new record low in 2012. Compared to the 2007 low, the SIE spatial pattern of the 2012 record low was slightly different with more sea ice coverage in some parts of the central Arctic Ocean and less coverage in the Beaufort, western Laptev, and East Greenland Seas, and parts of the
Canadian Archipelago (NSIDC-Arctic Sea Ice News and Analysis). Therefore it is desirable to investigate the atmospheric conditions and parameters during the summer of 2012, and compare them with those in 2007. As illustrated in Fig. 4a, b, the synoptic and wind patterns in 2012 were significantly different from those in 2007. Low pressure systems covered the entire Arctic with two centers located at Chukchi-Beaufort seas and Svalbard Islands, resulting in weak anomalous northerly winds over most of the AOF and the Fram Strait. The former suppressed the 2012 record low, while the latter was similar to that in 2007 (Fig. 3b). Although the patterns and signs of the anomalies of the atmospheric parameters in 2012 are the same as those in 2007, their magnitudes are much smaller.

Without the trigger of abnormal synoptic and wind patterns and strong enhancement of positive cloud-radiation-PWV feedback, what else caused the 2012 record low? NSIDC has shown that less old ice (more seasonal ice) for 2012 versus 2007 is the primary reason for the 2012 record low, while a super storm over the central Arctic Ocean in early August attributed to more ice break-up and ultimately led to this new record low. The thinner ice was more prone to mechanical ice deformation and ice melt by strong low pressure systems (Fig. 4a). Based on the comparison between 2007 and 2012, we can draw the following conclusion: the different extreme events may have different causes and mechanisms, however they all are related to the long-term thinning of Arctic sea ice and consequently dominating seasonal ice.

Figure 5 shows the inter-annual variations of the atmospheric parameters given in Figs. 3 and 4. As demonstrated in Fig. 5a, the year-to-year September sea-ice extents (SIEs) over the AOF prescribed in MERRA basically follow the variation of SIE derived from NSIDC with an average of $4.06 \%$ more during the period 1979-2012. The MERRA prescribed SIEs in 1996 and 2007 are nearly identical to the NSIDC SIEs. This comparison indicates that MERRA has comparable prescribed SIE to satellite observations and has the appropriate surface boundary forcing. Because of the general consistency of MERRA analysis with satellite observations on SIE as shown here and other key variables demonstrated by previous studies (Rienecker et al. 2011; Bosilovich et al. 2011), we use MERRA reanalyzed atmospheric parameters as an integrated part of our analysis in this study. Anomalies of the most relevant atmospheric parameters, such as meridional wind (V), SAT, PWV, CF, LWnet, andtotal surface energy budget, have the maximum positive and negative anomalies, respectively, during the summers $(6 / 15-9 / 15)$ of these 2 years compared to other years. Therefore the selected events in 2007 and 1996, as well as their relevant atmospheric parameters, are representative of two different extreme events during the period 1979-2012. 
Fig. 4 Same as Fig. 3 except for year 2012

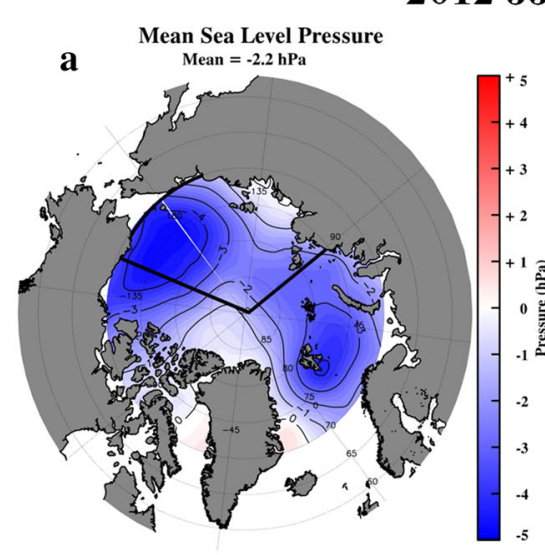

\section{JJAS}
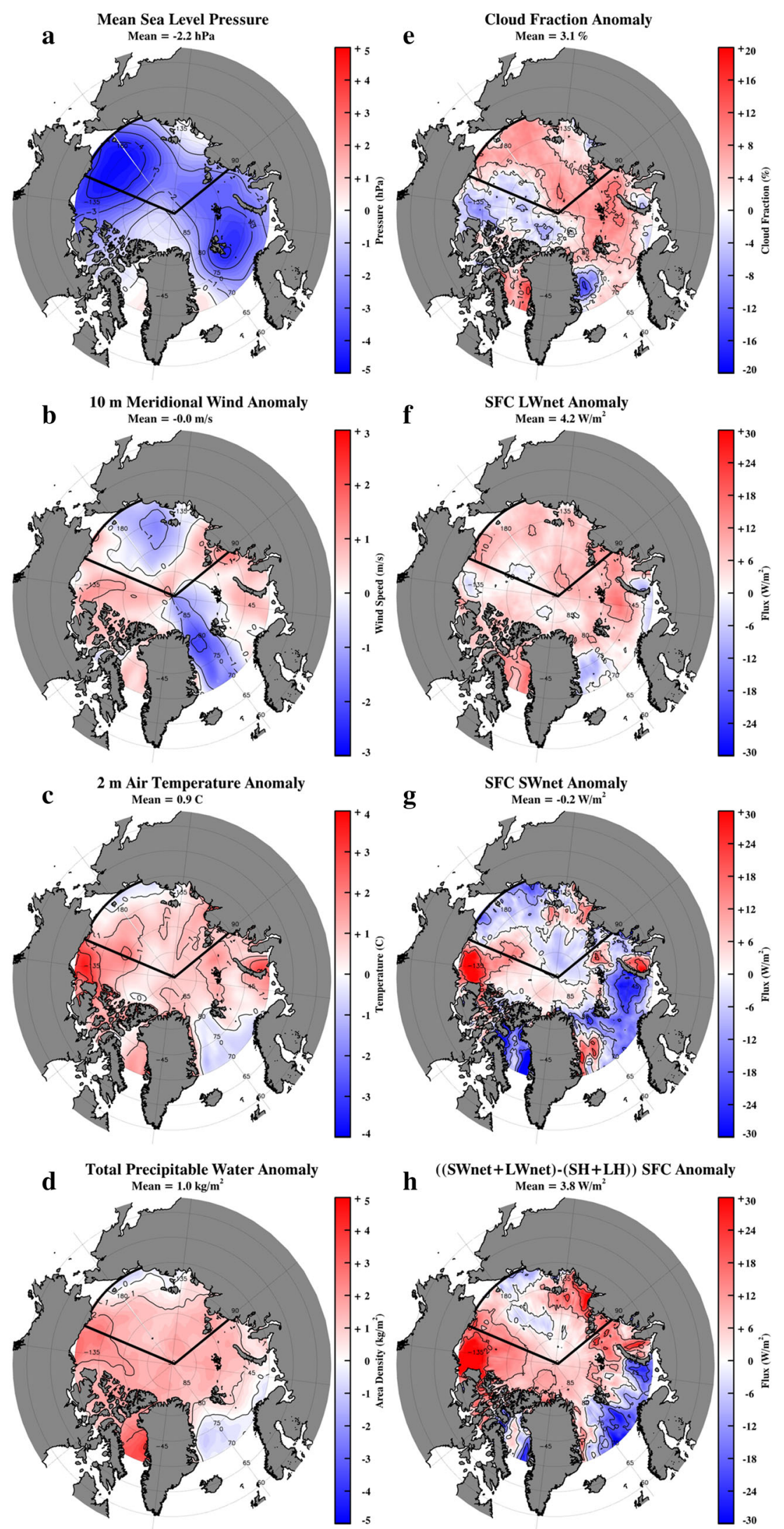

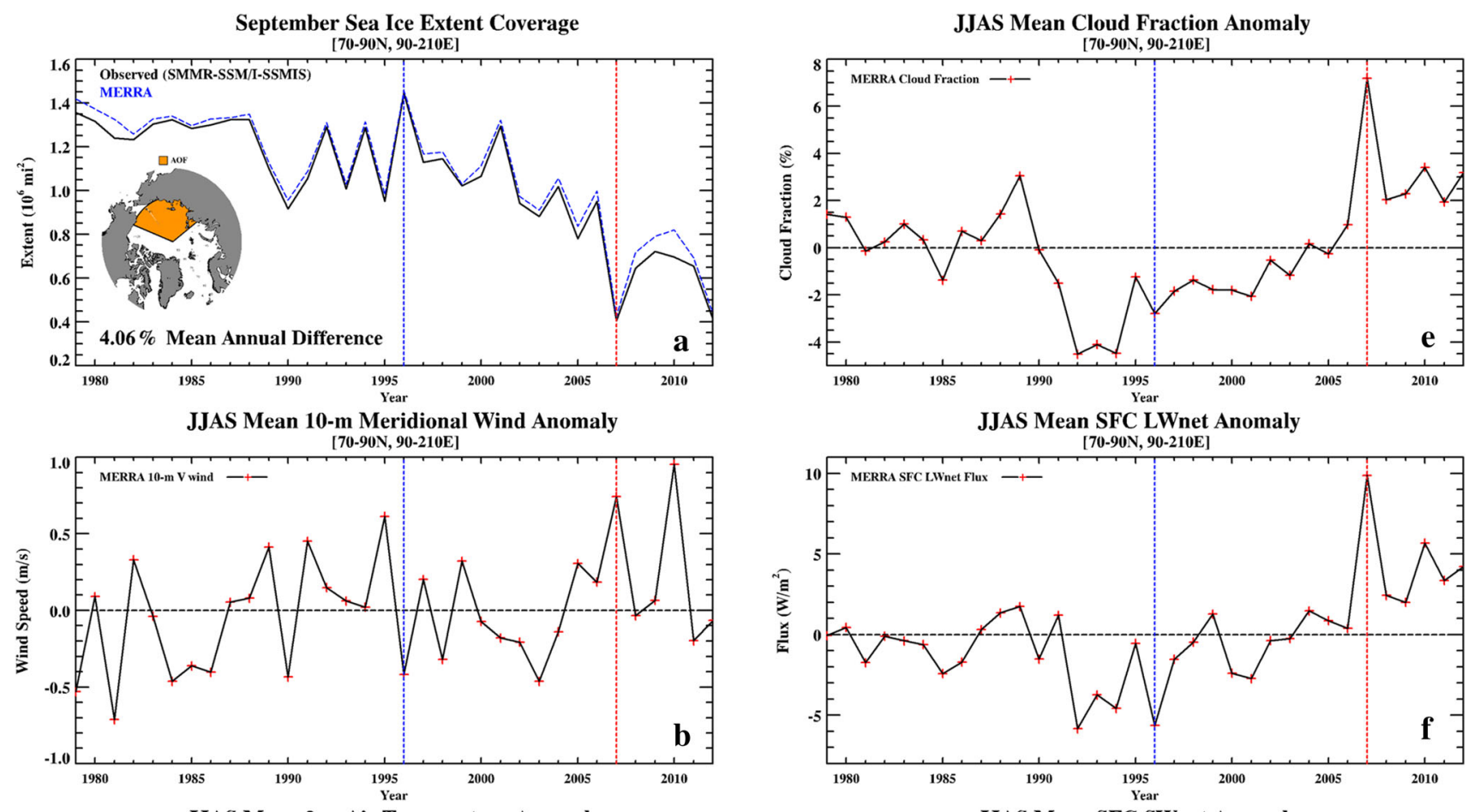

JJAS Mean 2 m Air Temperature Anomaly

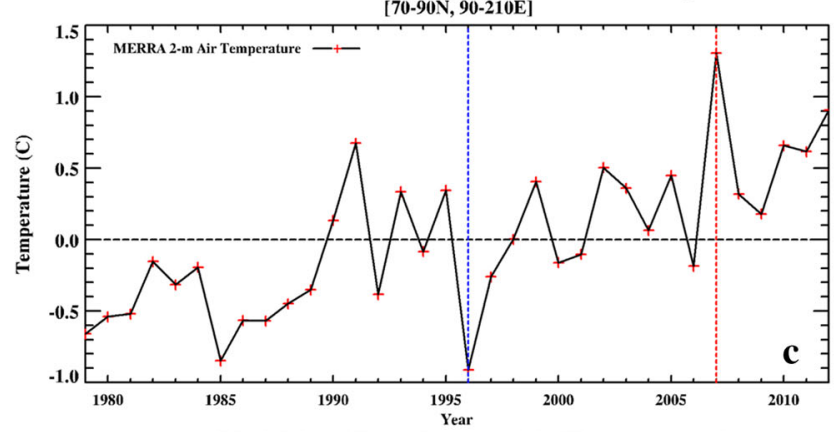

JJAS Mean Total Precipitable Water Anomaly
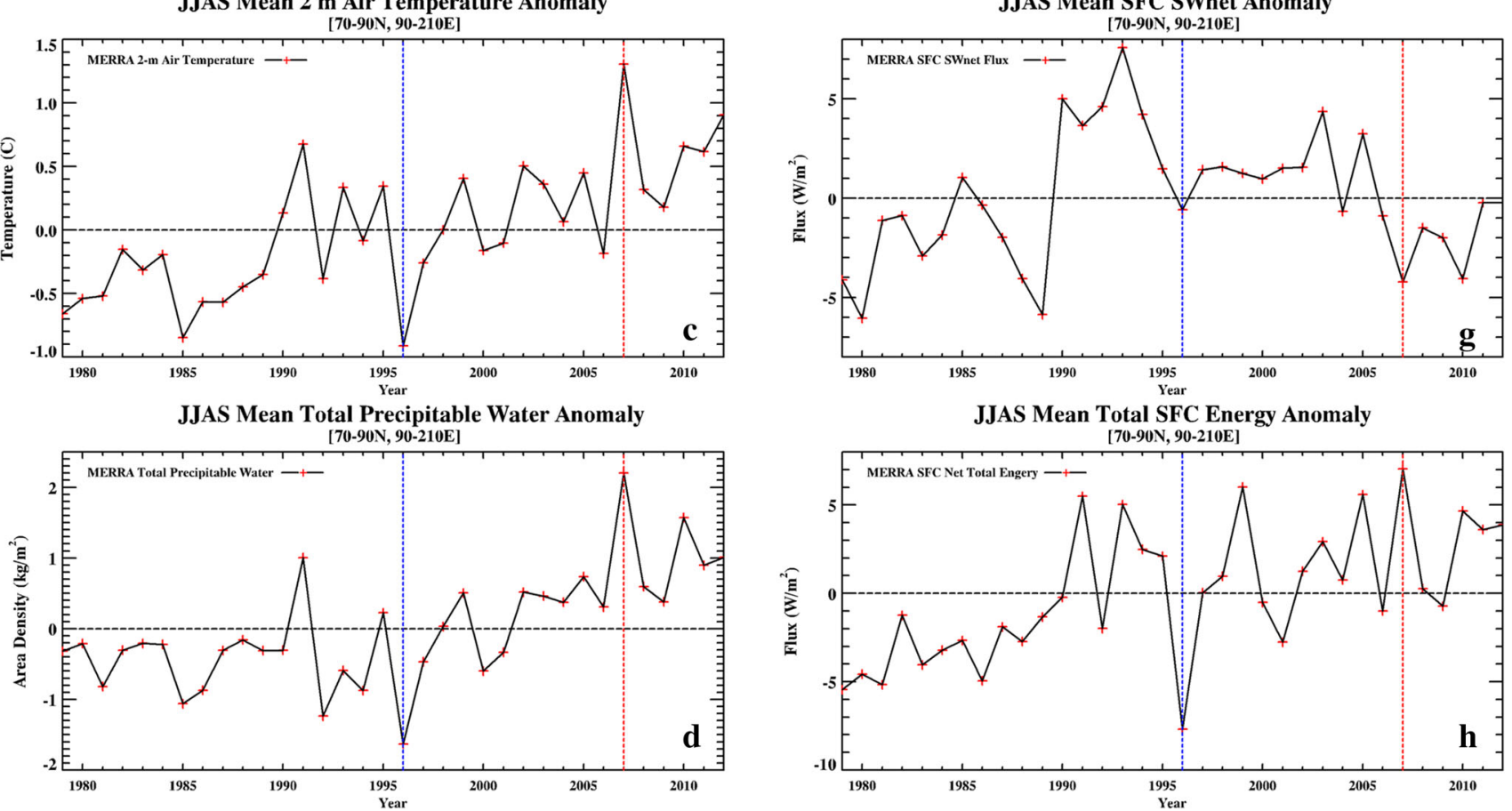

Fig. 5 a September SIEs over the AOF from Observed (black) and MERRA reanalysis (blue) from 1979 to 2012. The anomalies of the interested parameters averaged over the AOF during the period 6/15-9/15 (JJAS): b 10-m meridional wind speed (V), c 2-m air

Although the correlations between SIC and atmospheric parameters in other years are not as strong as those in 1996 and 2007, it is worth briefly discussing the impact of some extreme parameters on the SIE variation. For example, the meridional wind in 2010 was stronger than that in 2007, but

temperature (SAT), d precipitable water vapor (PWV), e cloud fraction $(\mathrm{CF}), \mathbf{f}$ surface LWnet, $\mathbf{g}$ SWnet, and $\mathbf{h}$ total surface energy budget

its SIE coverage over the AOF $\left(\sim 0.67 \times 10^{6} \mathrm{~km}^{2}\right)$ was much larger than that $\left(0.4 \times 10^{6} \mathrm{~km}^{2}\right)$ in 2007 as shown in Fig. 5a. Although the anomalies of atmospheric parameters in 2010 had the same sign as those in 2007, their magnitudes were much smaller than those in 2007, and close to 
Fig. 6 Monthly means (solid black line) and standard deviations (shaded area) for 1979-2012, 2007 (red) and 1996 (blue) (averaged over the AOF) of a sea-ice extent, b 10-m meridional wind speed V, c SAT, d PWV, e CF, f surface LWnet, g SWnet, h total surface energy fluxes, i $\mathrm{LH}$ and $\mathbf{j} \mathrm{SH}$
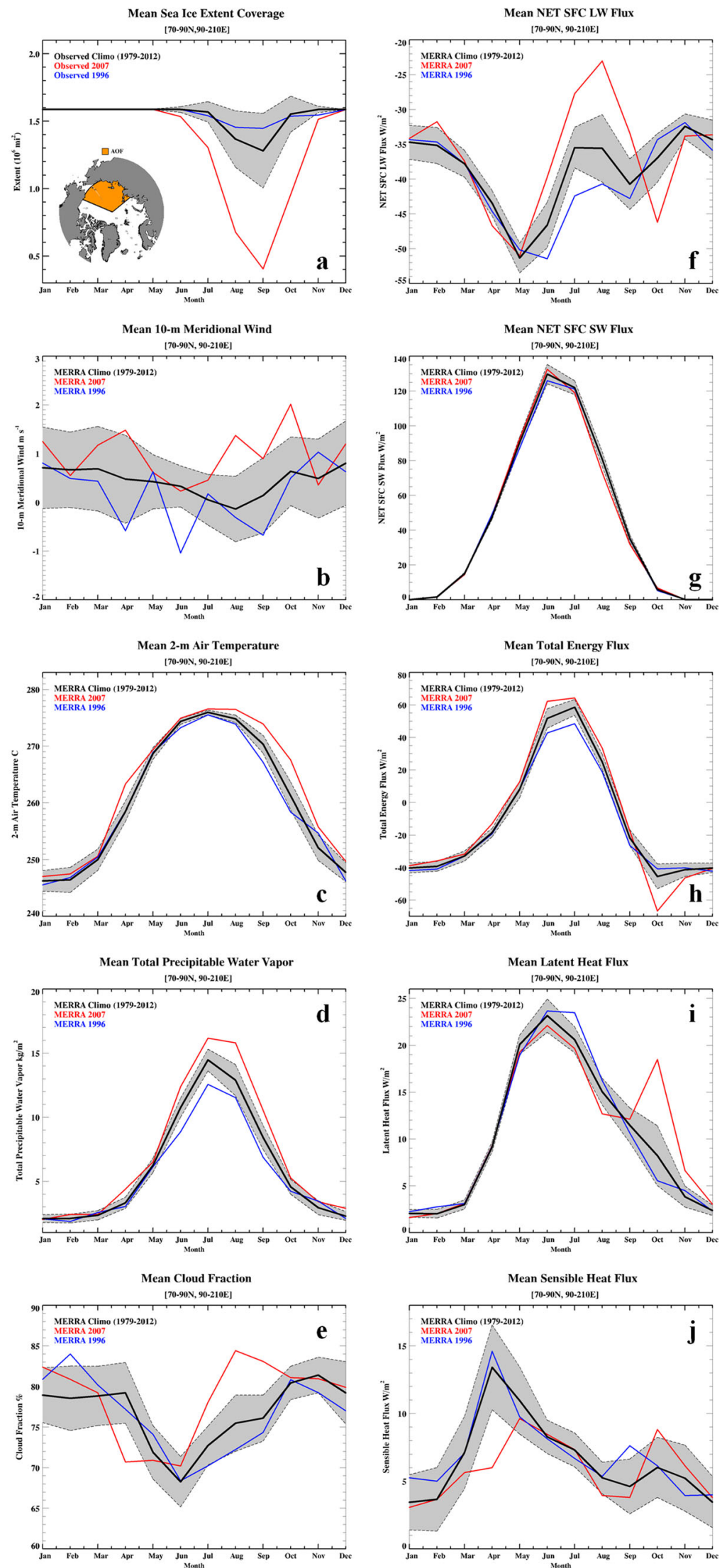
those in 2012. The most likely reason to explain this (the large SIE coverage in 2010) is lack of a strong positive cloud-radiation-PWV feedback process to enhance the sea ice retreat (as occurred in 2007) and/or a super storm to break the thinner sea ice (as occurred in 2012) although there were strong anomalous southerly winds to trigger the onset of Arctic sea ice in 2010. Another example is the period 1992-1994 where anomalies of CF and LWnet were close to, even lower than, those in 1996, while their SIEs did not reach the extent in 1996. The meridional winds over the AOF during the period 1992-1994 were weakly positive (southerly), and their SATs were warmer and SWnet and total surface energy budget were also positive too. All these positive anomalies suppressed the 1992-1994 SIEs to reach the extent in 1996.

To investigate the seasonal variations of the Arctic SIE and the relevant parameters, we plot in Fig. 6 the monthly means and standard deviations of Arctic SIE and the atmospheric parameters over the AOF for the period 1979-2012, and years of 2007 and 1996. As illustrated in Fig. 6a, the monthly means of SIE in 2007 were significantly lower (2-3 standard deviations) during the warm months (July-October). The monthly means of meridional wind $(\mathrm{V})$ were higher than its climatological value during spring months (March-May) with a peak in April, and second and third peaks in August and October (Fig. 6b). This result indicates that anomalous southerly winds occurred from March to October in 2007 except for June (slightly lower than the climatology but still southerly wind). PWV peaked during July-August (Fig. 6d) and both $\mathrm{CF}$ and LWnet reached their maximum values in August and were 2-3 standard deviations above their climatological values, while SWnet was almost the same as the climatology.

\section{Cloud-radiation-PWV feedback}

Motivated by the findings from the data analysis in Figs. 5 and 6 , and the maximum V, PWV, CF, and LWnet values occurring in different months, we investigate the mechanisms for triggering and causing the 2007 low, as well as the cloud-radiation-PWV feedback to the SIC variation. Through an integrative analysis of results, we found that the onset was triggered by the large-scale atmospheric circulation anomaly during spring, and then a drastic seaice reduction was reinforced by a positive cloud-radiationPWV feedback during the following summer and early autumn. To test this finding, we show in Fig. 7 the timeseries of the daily anomalies of SIC, V, SAT, PWV, CF, LWnet, SWnet, total surface energy, SH and LH averaged over the AOF from June 15 to September 15. Standard and partial correlations are calculated using the daily anomalies of SIC and relevant atmospheric parameters. Based on the results and discussions from Figs. 3, 5, 6 and 7, we quantitatively estimate the contribution made by the cloudradiation-PWV feedback to the SIC variation.

As illustrated in Fig. 6b, strong southerly winds occurred during the spring months, which brought more warm (higher SAT in April, Fig. 6c) and moist air (higher PWV in April, Fig. 6d) to the AOF. However, the CF, LWnet and SWnet during the spring were below or close to their climatological values. During the springtime, most of Arctic Ocean surfaces were still covered by sea ice, thus there are minimal interactions between ocean and atmosphere as demonstrated in their monthly means of latent heat flux (Fig. 6i). However, the sensible heat flux in April was $8 \mathrm{Wm}^{-2}$ lower than the climatology (less upward flux, Fig. 6j), resulting in $3-5 \mathrm{Wm}^{-2}$ more total surface energy (downward) than the climatology (Fig. 6h). This 3-5 $\mathrm{Wm}^{-2}$ extra energy during spring months, as well as $10 \mathrm{Wm}^{-2}$ extra energy in June (Fig. 6h), would be used to increase sea-ice and ocean temperatures, and melt sea-ice during the May-June months which triggered the onset of the 2007 low. Approximately $5 \mathrm{Wm}^{-2}$ extra surface heating amounts to a total of about $46.22 \times 10^{6} \mathrm{Jm}^{-2}$ extra heat in comparison to the climatology, which could melt about $138 \mathrm{~kg}$ of sea ice. The melted ice would reduce seaice coverage about $7.6 \%$ assuming an average sea-ice thickness of $2 \mathrm{~m}$ in the AOF [c.f. http://www.climatedata. info/Impacts/Impacts/Impacts/thickness.html], which is very close to the observed value $(\sim 10 \%$ in Fig. $7 \mathrm{a})$ considering uncertainties in net heat and sea-ice thickness estimates. The slight underestimate of the sea-ice reduction compared to the observation might indicate the presence of positive ocean heat transport anomalies during this period.

The warm and moist air transported from the North Pacific not only initiated sea-ice melting, but also increased PWV and formed more clouds over the AOF as demonstrated in Fig. 6e. When CF was high and Arctic surfaces were covered by snow and ice, particularly during the onset of sea-ice melting (May-June), the cloud-greenhouse (LW) effect overwhelmed the cloud-albedo (SW) effect due to the fact that cloud albedo is nearly the same as the surface albedo, producing a positive cloud radiative effect on surface radiation budget. The increased PWV has little effect on downwelling SW flux, but significantly increases downwelling LW flux (Dong et al. 2006; Philipona et al. 2005), further increasing the surface temperature and enhancing the sea-ice retreat. Later on, more sea-ice was melted, additional SW (and LW) radiation was absorbed by open seas to increase surface temperature, and more water vapor was evaporated to form more clouds, which strengthened further the positive cloud-radiation-PWV feedback. Therefore, the sea-ice retreat over the AOF was significantly accelerated due to the presence of this positive 

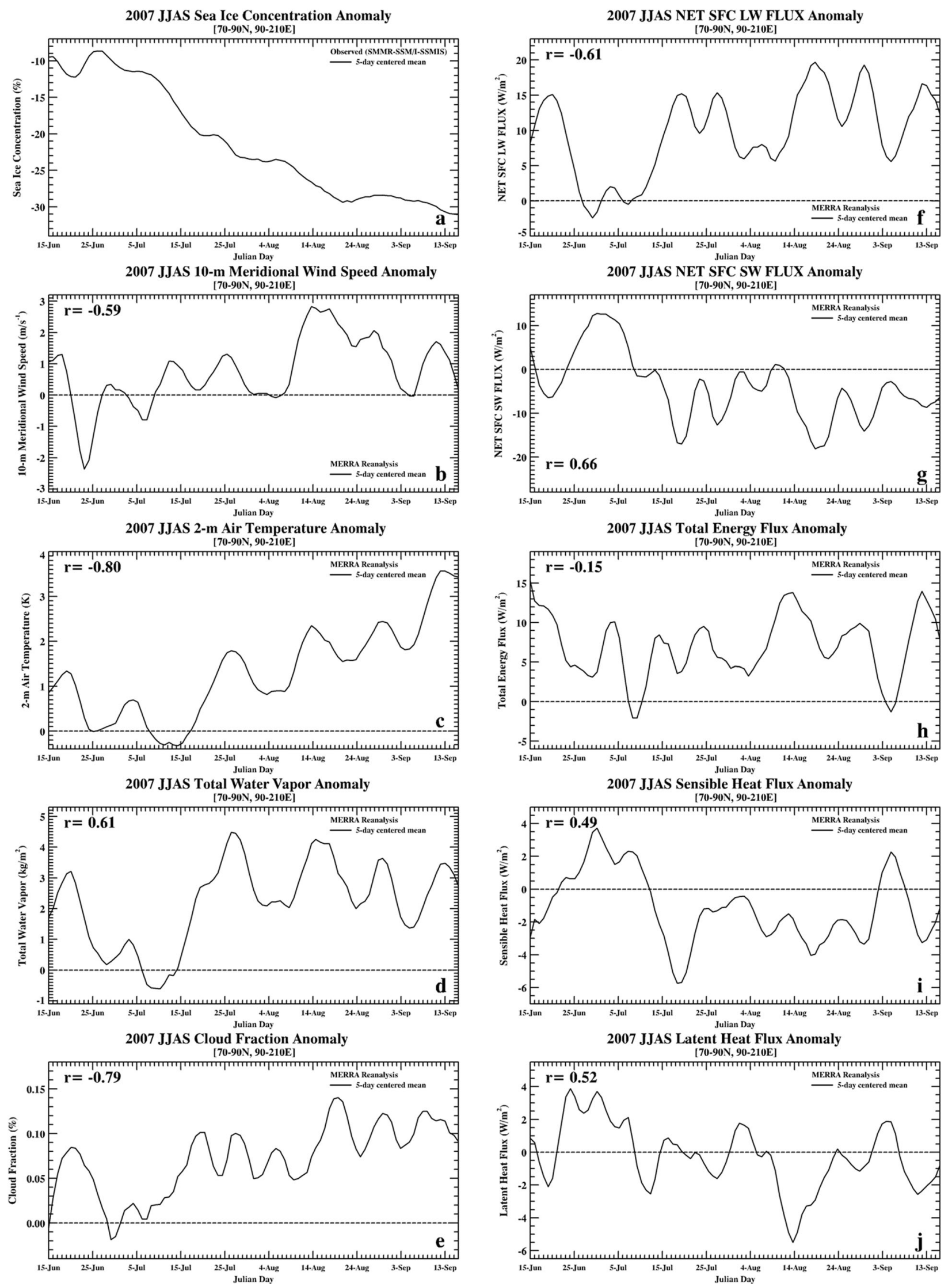
4 Fig. 7 Daily anomalies of a SIC, b V, c SAT, d PWV, e CF, f surface LWnet, $\mathbf{g}$ SWnet, $\mathbf{h}$ total energy budget, $\mathbf{i}$ LH and $\mathbf{j}$ SH over the AOF from June 15 to September 15, 2007. $\mathrm{R}$ values indicate the correlations of daily anomalies between SIC and each reanalyzed parameter

cloud-radiation-PWV feedback in the summer of 2007, and ultimately resulted in the 2007 low during the middle of September. The peaks of LH (Fig. 6i) and SH (Fig. 6j) in October of 2007 indicate that the AOF lost more energy when the SIE was still significantly below the climatic mean and meridional winds were anomalous high. The significant loss in total surface energy during October (Fig. 6h) helps the AOF SIE return to climatic state in November (Fig. 6a).

Figure 7 provides further evidences to support the effectiveness of this positive cloud-radiation-PWV feedback. The standard correlations between SIC and each atmospheric parameter in Fig. 7 were calculated from their daily anomalies over the AOF during the period June 15-September 15. As illustrated in Fig. 7a, the daily SIC anomalies went through the following three periods: (1) a small decrease $(0 \rightarrow-10 \%)$ from late May to late June with small fluctuations, (2) a significant drop $(-10 \% \rightarrow$ $-30 \%$ ) from late June to August 20th, and (3) a relatively stable period $(\sim-30 \%)$ until September 15 th. Figure 7 clearly demonstrates that the Arctic sea-ice retreat over the AOF was enhanced by this positive feedback, especially during the second period of SIC drop. During this period, strong southerly winds (Fig. 7b) brought much more warm (Fig. 7c) and moist air (Fig. 7d) from the North Pacific to the AOF. These warm and moist air masses interacted with open seas and formed more clouds (Fig. 7e). There is a strong positive correlation (0.87, not shown in Fig. 7) between $\mathrm{CF}$ and downwelling LWflux and a negative correlation $(-0.87)$ between CF and downwelling SW flux in this study. These relationships hold for LWnet and SWnet as shown in Fig. 7-when CF increased $15 \%$, LWnet increased about $20 \mathrm{Wm}^{-2}$ during this period. The decrease in SWnet, however, was not as pronounced as the increase in LWnet because downwelling SW flux was low when CF was high and also most of downwelling SW flux was absorbed by open seas, especially after mid-July. The positive cloud-radiation-PWV feedback process was also obvious during the last period of SIC drop after August 20th. During this period, the minimum SIC corresponds well with the significant increase in SAT, LWnet and total surface energy. The positive anomaly of total surface energy (more downward, Fig. 7h) with decreased upward SH and LH (Fig. 7i, j) during the second and third periods also contribute accelerating the sea-ice retreat and reach the minimum sea-ice during the middle of September.
To investigate each individual parameter's contribution to the SIC variation, we also calculated the partial correlations between SIC and atmospheric parameters after removing $\mathrm{CF}$ and $\mathrm{PWV}$ effects using the following equation:

$\gamma \mathrm{ABC}=\frac{\gamma \mathrm{AB}-\gamma \mathrm{AC} \gamma \mathrm{BC}}{\sqrt{(1-\gamma 2 \mathrm{AC})(1-\gamma 2 \mathrm{BC})}}$

The $\gamma_{\mathrm{ABC}}$ represents the partial correlation between SIC (A) and LWnet (B) after removing CF effect $(\mathrm{C})$, where $\gamma_{\mathrm{AB}}, \gamma_{\mathrm{AC}}$, and $\gamma_{\mathrm{BC}}$ are the standard correlations between SIC and LWnet, SIC and CF (shown in Fig. 7), and LWnet and $\mathrm{CF}$.

The high standard correlations (0.59-0.80 in Fig. 7) between SIC and each atmospheric parameter (such as V, SAT, PWV, CF, LWnet and SWnet) have demonstrated that meridional winds, water vapor, clouds, and radiation are indeed having significant impacts on the SIC variation. The partial correlations between SIC and LWnet (0.263) and SWnet $(-0.176)$ with $\mathrm{CF}$ effect removed are significantly lower than their corresponding standard correlations $(-0.61$ and 0.66) shown in Fig. 7. Furthermore, the removal of $\mathrm{CF}$ effect changes the sign of correlation between SIC and LWnet. Removing the PWV effect also drops the correlations between SIC and LWnet and SWnet to respectively -0.23 and 0.409 . This partial correlation analysis demonstrates the critical roles played by $\mathrm{CF}$ and PWV in establishing the observed connection between SIC and LWnet/SWnet.

The increased SAT along with a positive cloud-radiation-PWV feedback amplified the signal initiated by the atmospheric circulation anomaly, accelerated the sea-ice retreat during the summer of 2007, and ultimately resulted in the 2007 low. However, it is recognized here that modeling studies are needed to further confirm the feedback process and each parameter's contribution to the SIC variation.

\section{Summary and conclusions}

In this study, we examine two highly contrasting extreme events (2007 and 1996) in the September Arctic sea-ice extent using satellite observed sea-ice extent/concentration and the MERRA reanalysis. The impacts of meridional winds, water vapor, clouds, and radiation on the formation of these two extreme events are analyzed and the dynamical and physical processes triggering and accelerating the 2007 low are investigated. The SIE spatial pattern of the 2012 record low and its atmospheric conditions and parameters are also compared with those in 2007. The analysis has focused on the area of Laptev, East Siberian and Chukchi seas $\left(70-90^{\circ} \mathrm{N}, 90-210^{\circ} \mathrm{E}\right)$, which 
experiences the largest year-to-year variation in SIE, and was defined as the AOF. Main conclusions and findings from this study include:

1. The 2007 low was associated with positive anomalies of surface air temperature (SAT), precipitable water vapor (PWV), cloud fraction (CF), surface LWnet, and total surface energy over the AOF. A persistent anticyclone positioned over the Beaufort Sea coupled with low pressure over Eurasia induced anomalous southerly winds that transported ample warm and moist air from the North Pacific to the AOF, triggered sea-ice melting across the AOF and increased the Transpolar sea-ice drift out of the Arctic Ocean through the Fram Strait. This conclusion has confirmed the findings of previous studies. The new finding from this study is that we found the summers of 1996 and 2007 as contrasting examples of two circulation patterns with spatially opposite effects on winds, clouds, the surface heat balance, and SIE using MERRA reanalysis.

2. Another new finding from this study is the feedback mechanisms that triggered and enhanced the 2007 low. Although other studies did this kind of research, this study has discussed the possible feedback mechanisms between Arctic sea-ice variation and the atmospheric forcing fields with more comprehensive atmospheric parameters. The positive cloud-radiation-PWV feedback is discussed as follow. The onset was triggered by the large-scale atmospheric circulation anomaly during the spring months of 2007. Strong southerly winds brought warm and moist air from the North Pacific, which not only initiated sea-ice melting, but also increased PWV and formed more clouds over the AOF, particularly over open seas. When CF was high and Arctic surfaces were covered by snow and ice, particularly during the onset of sea-ice melting (MayJune), the cloud-greenhouse (LW) effect overwhelmed the cloud-albedo ( $\mathrm{SW}$ ) effect, producing a positive cloud radiative effect on the surface radiation budget. Downwelling LW flux increased significantly with increased PWV, generating another positive feedback to increase surface temperature and enhance sea-ice retreat. Later on, as more sea-ice was melted, additional SW (and LW) radiation was absorbed by open seas to increase surface temperature, and more water vapor evaporated to form more clouds, which further enhanced the positive cloud-radiation-PWV feedback.

3. Compared to the 2007 low, the SIE spatial pattern of the 2012 record low was different with more SIE coverage in some parts of the central Arctic Ocean and less coverage in the Beaufort, western Laptev, and
East Greenland Seas, and parts of the Canadian Archipelago. The preliminary identified atmospheric forcing for the 2012 record low was neither characterized by anomalous synoptic weathers and wind patterns nor enhanced by the positive cloud-radiationPWV feedback. It was mainly triggered by a super storm centered over the central Arctic Ocean in early August. The low pressure system caused substantial mechanical ice deformation, attributed to more ice break-up and ultimately led to this new record low on top of the long-term thinning of an Arctic ice pack that had become more dominated by seasonal ice. The different driving forcings for the 2007 and 2012 events need further investigations in following up studies.

Finally, although we have demonstrated that the surface wind, surface energy budget, and associated surface conditions (sea ice or open water) played a critical role in causing the two opposite extreme events, changes in seaice dynamics and thermodynamics may have also made considerable contributions to these two events. For example, the long-term thinning of sea-ice thickness would be a preconditioning for the 2007 low. However, continuing thinning of sea ice in 2008 did not lead to another record low in 2008 because of lack of a super storm triggering the thinner sea ice (as occurred in 2012). Sea-ice extent was slightly recovered after 2007. Thus, complex interactions between sea-ice physics and overlying atmospheric and underlying oceanic processes need quantitative and synthetic investigations through a broad spectrum of research approaches.

Acknowledgments This work is supported by the National Basic Research Program of China (973 Program, 2013CB955804) at Beijing Normal University. Researchers at University of North Dakota were supported by NASA EPSCoR CAN under Grant NNX11AM15A at University of North Dakota. The Georgia Tech co-author (Deng) was supported by the NASA NEWS under Grant NNX09AJ36G. X. Zhang was funded by the NSF through the Grant \# ARC 1023592 and 1107509. Dr. Long acknowledges the support of the Climate Change Research Division of the US Department of Energy as part of the Atmospheric System Research (ASR) Program.

Open Access This article is distributed under the terms of the Creative Commons Attribution License which permits any use, distribution, and reproduction in any medium, provided the original author(s) and the source are credited.

\section{References}

Amback W (1974) The influence of cloudiness on the net radiation balance of a snow surface with high albedo. J Glac 13:73-84

Bloom SC, Takacs LL, DaSilva AM, Ledvina D (1996) Data assimilation using incremental analysis updates. Mon Weather Rev 124:1256-1271 
Bosilovich MG, Chen J, Robertson FR, Adler RF (2008) Evaluation of global precipitation in reanalyses. J Appl Meteorol Clim 47:2279-2299

Bosilovich MG, Robertson FR, Chen J (2011) Global energy and water budgets in MERRA. J Clim 24:5721-5739

Cavalieri D, Thorsten M, Comiso J (2004) Updated daily AMSR-E/ aqua daily L3 $25 \mathrm{~km}$ brightness temperature and sea ice concentration polar grids V002, [May2007-Sep 2007]. National Snow and Ice Data Center. Digital media, Boulder, CO

Chou MD, Suarez MJ (1999) A solar radiation parameterization for atmospheric studies. NASA technical report series on global modeling and data assimilation 104606, vol 15, p 40

Chou MD, Suarez MJ, Liang XZ, Yan MMH (2001) A thermal infrared radiation parameterization for atmospheric studies. NASA technical report series on global and data assimilation 104606, vol 19, p 56

Comiso JC, Parkinson CL, Gersten R, Stock L (2008) Accelerated decline in the Arctic sea ice cover. Geophys Res Lett 35:L01703

Cullather RI, Bosilovich MG (2011) The moisture budget of the polar atmosphere in MERRA. J Clim 24:2861-2879

Cullather RI, Bosilovich MG (2012) The energy budget of the polar atmosphere in MERRA. J Clim 25:5-24

Curry JA, Rossow WB, Randall D, Schramm JL (1996) Overview of Arctic cloud and radiation characteristics. J Clim 9:1731-1764

Cuzzone J, Vavrus S (2011) The relationships between Arctic sea ice and cloudrelated variables in the ERA-Interim reanalysis and CCSM3. Environ Res Lett 6:014016. doi:10.1088/1748-9326/6/ $1 / 014016$

Deser C, Walsh JE, Timlin MS (2000) Arctic sea ice variability in the context of recent atmospheric circulation trends. J Clim $13: 617-633$

Dong X, Xi B, Minnis P (2006) A climatology of midlatitude continental clouds from ARM SGP site. Part II: cloud fraction and surface radiative forcing. J Clim 19:1765-1783

Dong X, Xi B, Crosby K, Long CN, Stone R, Shupe M (2010) A 10-year climatology of Arctic cloud fraction and radiative forcing at barrow, Alaska. J Geophys Res 115:D17212

Donohoe A, Battisti DS (2011) Atmospheric and surface contributions to planetary albedo. J Clim 24(16):4402-4418. doi:10. 1175/2011JCLI3946.1

Drobot S, Stroeve J, Maslanik J, Emery W, Fowler C, Kay J (2008) Evolution of the 2007-2008 Arctic sea ice cover and prospects for a new record in 2008. Geophys Res Lett 35:L19501. doi:10. 1029/2008GL035316

Francis JA, Hunter E (2006) New insight into the disappearing Arctic Sea ice. Eos Trans Am Geophys Union 87:509

Francis JA, Hunter E, Key J, Wang X (2005) Clues to variability in Arctic minimum sea ice extent. Geophys Res Lett 32:L21501

Giles KA, Laxon SW, Ridout AL (2008) Circumpolar thinning of Arctic sea ice following the 2007 record ice extent minimum. Geophys Res Lett 35:L22502. doi:10.1029/2008GL035710

Graversen RG, Mauritsen T, Drijfhout S, Tjernstrom M, Kallen E, Svensson G (2008) Vertical structure of recent Arctic warming. Nature 541:53-56

Graversen RG, Mauritsen T, Drijfhout S, Tjernstrom M, Martensson S (2011) Warm from the Pacific caused extensive Arctic sea-ice melt in summer 2007. Clim Dyn 36:2103-2112. doi:10.1007/ s00382-010-0809-z

Haas C, Eicken H (2001) Interannual variability of summer sea ice thickness in the Siberian and central Arctic under different atmospheric circulation regimes. J Geophys Res 106:4449-4462

Harder M, Lemke P, Hilmer M (1998) Simulation of sea-ice transport through Fram Strait: natural variability and sensitivity to atmospheric forcing. J Geophys Res 103:5595-5606

Intrieri JM, Fairall CW, Shupe MD, Persson POG, Andreas EL, Guest PS, Moritz RE (2002) An annual cycle of Arctic surface cloud forcing at SHEBA. J Geophys Res 107. doi:10.1029/2000 JC000439

Kay JE, Gettleman A (2009) Cloud influence on and response to seasonal Arctic sea ice loss. J Geophys Res 114:D18204

Kay JE, L'Ecuyer T, Gettleman A, Stephens G, O'Dell C (2008) The contribution of cloud and radiation anomalies to the 2007 Arctic sea ice extent minimum. Geophys Res Lett 35:L08503. doi:10. 1029/2008GL033451

Kennedy JJ, Titchner HA, Hardwick J, Beswick M, Parker DE (2007) Global and regional climate in 2007. Weather 62:232-242

Kwok R (2008) Summer sea ice motion from the $18 \mathrm{GHz}$ channel of AMSR-E and the exchange of sea ice between the Pacific and Atlantic sectors. Geophys Res Lett 35:L03504

Levermann A, Mignot J, Nawrath S, Rahmstorf S (2007) The role of northern sea ice cover for the weakening of the thermohaline circulation under global warming. J Clim 20:4160-4171

Lin B, Minnis P, Fan TF, Hu Y, Sun W (2010a) Radiation characteristics of low and high clouds in different oceanic regions observed by CERES and MODIS. Int J Remote Sens 31:6473-6492. doi:10.1080/01431160903548005

Lin B, Chambers L, Stackhouse P Jr, Wielicki B, Hu Y, Minnis P, Loeb N, Sun W, Potter G, Min Q, Schuster G, Fan TF (2010b) Estimations of climate sensitivity based on top-of-atmosphere radiation imbalance. Atmos Chem Phys 10:1923-1930

Lindsay RW, Zhang J, Schweiger AJ, Steele MA, Stern H (2009) Arctic sea ice retreat in 2007 follows thinning trend. J Clim 22:165-176. doi:10.1175/2008JCLI2521

Maslanik JA, Fowler C, Stroeve J, Drobot S, Zwally J, Yi D, Emery W (2007a) A younger, thinner Arctic ice cover: increased potential for rapid, extensive sea-ice loss. Geophys Res Lett 34:L24501

Maslanik JA, Drobot S, Fowler C, Emery W, Barry R (2007b) On the Arctic climate paradox and the continuing role of atmospheric circulation in affecting sea ice conditions. Geophys Res Lett 34:L03711

Ogi M, Rigor IG, McPhee MG, Wallace JM (2008) Summer retreat of Arctic sea ice: role of summer winds. Geophys Res Lett 35:L24701

Ohmura A et al (1998) Baseline Surface Radiation Network (BSRN/ WCRP): new precision radiometery for climate change research. Bull Am Meteorol Soc 79:2115-2136

Overland JE, Wang M (2010) Large-scale atmospheric circulation changes associated with the recent loss of Arctic sea ice. Tellus 62A:1-9

Overland JE, Wang M, Salo S (2008) The recent Arctic warm period. Tellus 60A:589-597

Peixoto JP, Oort AH (1992) Physics of climate. American Institute of Physics, New York, p 520

Perovich DK, Richter-Menge JA, Jones KF, Light B (2008) Sunlight, water, and ice: extreme Arctic sea ice melt during the summer of 2007. Geophys Res Lett 35(11):L11501

Philipona R, Dürr B, Ohmura A, Ruchstuhl C (2005) Anthropogenic greenhouse forcing and strong water vapor feedback increase temperature in Europe. GRL 32. doi:10.1029/2005GL023624

Polyakov IV et al (2010) Arctic Ocean warming contributes to reduced polar ice cap. J Phys Oceanogr 40:2743-2756. doi:10. 1175/2010JPO4339.1

Porter DF, Cassano JJ, Serreze MC, Kindig DN (2010) New estimates of the large-scale Arctic atmospheric energy budget. J Geophys Res-Atmos 115. doi:10.1029/2009JD012653

Porter DF, Cassano JJ, Serreze MC (2011) Analysis of the Arctic atmospheric energy budget in WRF: a comparison with reanalyses and satellite observations, J Geophys Res 116(D22). doi:10. 1029/2011JD016622

Richter-Menge J et al (2008) Arctic report card 2008. http://www. noaa/arctic/gov/reportcard/ 
Rienecker MM et al (2008) The GEOS-5 data assimilation systemdocumentation of versions 5.0.1, 5.1.0, and 5.2.0. Technical report series on global modeling and data assimilation 104606, vol 27

Rienecker MM et al (2011) MERRA: NASA's modern-era retrospective analysis for research and applications. J Clim 24:3624-3648

Robertson FR, Bosilovich MG, Chen J, Miller TL (2011) The effect of satellite observing system changes on MERRA water and energy fluxes. J Clim 24:5197-5217

Schweiger AJ, Zhang J, Lindsay RW, Steele M (2008) Did unusually sunny skies help drive the record sea ice minimum of 2007? Geophys Res Lett 35:L10503

Shimada K, Kamoshida T, Itoh M, Nishino S, Carmack E, McLaughlin FA, Zimmermann S, Proshutinsky A (2006) Pacific Ocean inflow: influence on catastrophic reduction of sea ice cover in the Arctic Ocean. Geophys Res Lett 33:L08605. doi:10. 1029/2005GL025624

Stroeve J, Holland MM, Meier W, Scambos T, Serreze M (2007) Arctic sea ice decline: faster than forecast. Geophys Res Lett 34:L09501

Vavrus S, Holland MM, Jahn A, Dailey DA, Blazey BA (2012) 21stcentury Arctic climate change in CCSM4. J Clim 25:2676-2695

Zhang J, Lindsay R, Steele M, Schweiger A (2008a) What drove the dramatic retreat of arctic sea ice during summer 2007? Geophys Res Lett 35:L11505

Zhang X, Sorteberg A, Zhang J, Gerdes R, Comiso JC (2008b) Recent radical shifts of atmospheric circulations and rapid changes in Arctic climate system. Geophys Res Lett 35:L22701

Zib B, Dong X, Xi B, Kennedy A (2012) Evaluation and intercomparison of cloud fraction and radiative fluxes in recent reanalyses over the Arctic using BSRN surface observations. J Clim 25:2291-2305 